Samoa, but in the other Administrations it is probable that increased salary and allowances will be given during the actual period of service and that no pensions will be granted.

The native medical practitioners receive salaries varying from $£ 60$ to $£ 150$ per annum, which apparently meet their wants adequately. They are medical officers and do not seek private practice as we understand it. Their journal, The Native Medical Practitioner, is an excellent publication which will interest any European practitioner.

In the Tropical Diseases Bulletin of November 1936 a detailed account of the working of the Central School is published by Dr. Clunie (Medical Superintendent of the Colonial War Memorial Hospital, Suva) and Dr. McGusty (late Inspecting Medical Officer, Fiji). The Islands served contain about 500,000 people, and at present there are 84 medical practitioners distributed as follows: Fiji 56, Samoa (Western) 9, Samoa (Eastern) 0, Tonga 4, Cook Island 2, Gilbert and Ellice 10, Solomon Islands 2, New Hebrides 1, total 84 ; native obstetric nurses, Fiji, 47.

Their conclusion is as follows : "Taken individually the Administrations participating in the Native Medical Practitioner scheme have not the means to embark on elaborate enterprises to provide adequate medical services, but by a pooling of their resources, as is now the case at the Central Medical School, it is felt that they will be able to elaborate a common form of health organization that will bestow further benefits on the native peoples. In Fiji the system has proved successful after a long and searching trial, and if it is too early yet to claim the same success with regard to its more recent ramifications into the other Pacific Administrations, the similarity of conditions and the favourable reports that are coming to hand appear to provide full justification for the confidence which those of us who are in the closest touch feel with regard to the future of the Native Medical Practitioner in the Pacific. As the system becomes more permanently established everywhere it will suffer progressively less from the effects of destructive criticism, but there will always remain the danger that some over-enthusiastic supporters may lose sight of the fundamental cause of its success and in a misguided attempt to raise the status of the Native Medical Practitioner may defeat the purpose for which the school was created, namely to make a health service available to these native peoples at a low cost and in the form that is most easily assimilable by their society."

The School is administered economically, the average cost per student being about $£ 75$ per annum; that is, total cost about $£ 3,000$ per annum. Amongst the many tributes to the efficiency of the School place must be given to the observation of Prof. Buckmaster and Dr. Wright made after a visit to the School when returning to England in 1931 from Australasia. Their comment was as follows: "The Hospital and Medical School at Suva for Natives of Fiji, Samoa and Other Tslands is really a wonderful place to find in the South Pacific. We not only saw all over the Hospital, but conducted a short class in anatomy and physiology in the School and both thought the students equal to what we might have expected to find in an ordinary Medical School in London. Indeed we were both astonished at the information they had acquired. I ask how many Englishmen know anything about this remarkable Hospital in Fiji ?"

In conclusion I have one caution to emphasize. If enthusiastic people try to extend the course and to increase the expense, much damage may be done in seeking something economically impossible. There is, I am glad to say, no evidence at present of any such intention. Depopulation has ceased in Fiji and with prudent administration the Central School may prevent depopulation in the other Islands. I am very grateful to Dr. A. H. B. Pearce, Principal Medical Officer, Fiji, and his staff for the information furnished on several visits, for the personal contact obtained with these fine young men and for many reports.

\title{
The Radio Exhibition at Olympia
}

\begin{abstract}
$7 \mathrm{HE}$ annual radio exhibition at Olympia, which this year was held on August 25-September 4, is generally a partial disappointment to those interested in the scientific and technical aspects of broadcasting, as it is usually quite difficult to ascertain what technical progress and improvements are being displayed. The exhibition is largely an elaborate display of the external cabinets, although most firms nowadays provide simple means for inspecting the internal construction and layout of the receiver itself. This year there was abundant evidence to show that most manufacturers have realized that the modern broadcast receiver has to take its place as an article of domestic furniture, and as such it must not be made especially conspicuous by its curious shape and appearance. Another notable advance in what may be termed the external features of the receiver is constituted by the enlargement of the tuning scale and its ease of operation. There is, however, still room for greater uniformity in the location of the control knobs among receivers of different makes.
\end{abstract}

In order to appreciate the improvements made in the internal portion of broadcast receivers, the visitor to the exhibition was fortunate in having as a guide the detailed reports given by such technical journals as the Wireless World, which has published three special show numbers on this occasion. A general survey of this year's exhibits of the various manufacturers indicates that many fundamental features of the broadcast receiver have become sufficiently stabilized for the designer to concentrate upon the steady improvement of detail. The great majority of receivers now manufactured are of the supersonic heterodyne type, since this provides both the sensitivity and the selectivity required by modern broadcasting conditions. The selectivity has now generally been made adequate by the incorporation of a properly tuned amplifying stage operating at the incoming signal frequency. A noteworthy advance this year is the incorporation of a correctly designed short-wave range as a standard feature; and the division of the short-wave broadcasting band into 
two ranges is a factor which adds considerably to the ease of operation of the receivers so fitted. Those familiar with difficulties of tuning in short-wave stations will also appreciate the improvements in the mechanical portion of the slow-motion drive to the tuning condensers, as well as the large easily read scale which is generally provided nowadays. Several of the receivers shown at the exhibition were provided with a wave-length range in the ultra-short wave band, so that they may be used for the reception of the sound portion of the television programmes.

This year's exhibition was not so conspicuous as some of the previous ones for radical modifications in the types of valves incorporated in receivers, but two points here are worthy of note. The development of the tetrode output valve has caused the rating of most mains-operated receivers to be raised from the previous value of 2-3 watts to 5 watts or above. Secondly, one manufacturer of an all-wave supersonicheterodyne receiver is experimenting with the use of theHarries all-stage valve. In this receiver all six valves are of the same seven-electrode type, the valves being adapted for their functions in the various stages by suitable external connexion to the electrodes. It will be interesting to observe the results of this innovation, since the advantages of using the same type of valve in any position in a receiver are self-evident.

In the case of battery-operated sets, the main problem all the time is to obtain sufficient output of good quality without overloading the normal hightension battery, the size of which has now become fairly well standardized. Although the output from such receivers seldom exceeds half a watt nowadays, considerable improvement in acoustic sensitivity has been attained by the use of improved magnetic alloys for the small permanent magnet loud-speakers generally employed in such sets. There is ample evidence that the portable wireless receiver has still a wide field of service, and the attractions of several of this year's models are enhanced by the inclusion of a properly designed short-wave range.

Probably the most interesting feature of Radiolympia this year, from a technical point of view, was the fact that more than a dozen manufacturers showed fully developed television receivers suitable for the programmes now regularly provided from the London station. Direct reception of these programmes was carried out at the exhibition, and facilities were provided for each firm to give demonstrations to the public under comfortable viewing conditions. So far, little uniformity is noticeable in the design of the television receivers produced by the different manufacturers, although they naturally all employ the cathode ray tube for the reproduction of the picture image. There is a tendency to favour the use of the supersonic heterodyne receiver, although in a number of sets the amplification is carried out at the ultra-high frequency employed for the television service. There is as yet no uniformity in the methods employed for the control of the electron beam in the cathode ray tube, as both mag. netic and electric methods are employed for focusing and deflection. One of the most interesting television receivers exhibited employs a tube of only 4 inches diameter; the image produced on the fluorescent screen of this tube is projected on to an etched glass sereen giving a picture of size $20 \mathrm{in} . \times 16$ in. The more normal method, however, is to produce the final picture on the screen of the cathode ray tube and to view this either directly or through an inclined mirror. The normal size of picture for receivers priced at 60 guineas upwards is about 10 in. $\times 8$ in. ; but some cheaper receivers are now available giving a picture size of about $7 \frac{1}{2}$ in. $\times 6$ in. With the view of obtaining the utmost economy in the production of a television receiver, one type shown provides the circuits for the vision signal only, a normal broadcast receiver being required in addition to reproduce the sound accompaniment. In this way, a receiver giving a picture about 6 in. $\times 4 \frac{1}{2}$ in. in size can be obtained for about $£ 35$. This is a development likely to be worth exploring in the attempt to produce a television receiver at a price sufficiently low to appeal to a large number of listeners who already possess a normal broadcasting receiver.

In concluding this review of the exhibition organized by the Radio Manufacturers Association, mention must be made of the interesting museum provided to illustrate the evolution of the modern broadcasting receiver, and of the extension to the television field of the interesting demonstrations provided by the Post Office to illustrate the deleterious effect of various classes of electrical interference on the conditions of broadcast reception. Finally, it must not be forgotten that one of the most popular attractions of Radiolympia is the provision by the British Broad. casting Corporation of daily variety concerts in a specially constructed hall, which this year contained accommodation for an audience of more than 5,000 .

R. L. S.-R.

\section{Isotopes of Strontium}

$\mathrm{W}^{\circ}$ ORK on the isotopes of strontium has recently been reported by Mattauch, and by Hahn and co-workers. Mattauch (Naturwiss., 25, 170; 1937) has determined the packing fractions of the isotopes ${ }^{86} \mathrm{Sr}$ and ${ }^{87} \mathrm{Sr}$ by the doublet method, using ${ }^{29} \mathrm{SiF}_{3}$ and ${ }^{30} \mathrm{SiF}_{3}$, respectively, for comparison. Using the data of other workers for the masses of ${ }^{29} \mathrm{Si}$ and ${ }^{30} \mathrm{Si}$, the packing fraction of ${ }^{87} \mathrm{Sr}$ is found to be $-8 \cdot 7 \pm 0 \cdot 3$, and its mass $86 \cdot 924_{3} \pm 0 \cdot 004$. The packing fraction of ${ }^{86} \mathrm{Sr}$ is $-9 \cdot 0 \pm 0 \cdot 5$, and its mass $85 \cdot 922_{6} \pm 0 \cdot 004$.

The radioactive transformation of rubidium into the strontium isotope of mass 87 has been investigated by Hahn, Strassmann and Walling (Naturwiss., 25, $189 ; 1937)$, who examined the strontium occurring in a mica from Silver-leaf mine, Manitoba. The mica was comparatively rich in rubidium (containing 2-3 per cent of it), but contained only a very minute amount (a few hundredths of a per cent) of alkali earth metals. Careful treatment of the mineral resulted in the isolation of $250 \mathrm{mgm}$. of strontium carbonate. If rubidium breaks down by radioactive disintegration to give strontium, it would be expected that the product of disintegration would be present in the mineral in comparatively small amount. As alkali earth metals were actually almost entirely absent, it is very likely that the small quantity of strontium present was derived from this disintegration. The geological age of the mica is estimated at 